\title{
The Cumberlage ban - slings work differently from mesh sheets and should be restored
}

\author{
Peter Petros ${ }^{1}$ \\ ${ }^{1}$ University of Western Australia
}

November 9, 2020

\section{COMMENTARY}

TITLE PAGE

The Cumberlage ban - slings work differently from mesh sheets and should be restored.

Author Peter Petros

${ }^{1}$ Petros P email pp@kvinno.com

31/93 Elizabeth Bay Rd

ELIZABETH BAY

NSW 2011

AUSTRALIA

${ }^{1}$ School of Mechanical and Chemical Engineering University of Western Australia

Mob. +61 411181731

*Corresponding author ${ }^{1}$ Petros P email pp@kvinno.com

${ }^{1}$ School of Mechanical and Chemical Engineering University of Western Australia

Running title Slings work differently from mesh sheets

No of words 977

\section{Comment}

Earlier this year, all mesh sling and mesh kits were banned from the UK following the Cumberlage report. We should all support the Cumberlage banning of mesh sheets, but not slings ${ }^{1,2}$. I write as the co-inventor of the midurethral sling ${ }^{1}$ (MUS)] to present the historical and other scientific data which supports retention of the MUS. Slings work very differently from mesh sheets. They create new collagen to strengthen the ligaments which suspend the organs, fig1. A tape placed along the anatomical pathway of the pubourethral ligament "PUL", fig1 cures stress urinary incontinence (SUI) by restoring the urethral closure mechanisms ${ }^{1,2,3}$. The same methodology holds for slings in other ligaments ${ }^{4}$. A multicentre trial of 616 women $^{4}$ demonstrated convincingly that mesh sheets are not required to cure major prolapse. Liedl et al reported $90 \%$ cure of vaginal prolapse (mostly $3^{\text {rd }}$ or $4^{\text {th }}$ degree) at 12 months using slings ONLY to repair cardinal and uterosacral ligaments. Vaginal herniations were re-attached, not excised. There were complications, some major, and erosion rates of $0-3 \%$. However, there was a singular absence of the massive urine loss and nerve pain entrapments seen in the mesh sheet operations which develop the "Tethered Vagina" syndrome by fibrosis of the vagina ${ }^{5,6}$. 
Mesh sheets restore neither structural anatomy nor function. They are an ill-proven initiative which relies on blocking descent of the organs. A simple transperineal ultrasound will prove that the prolapse is still there, behind the mesh. The mesh sheets fibrose the vagina, removing the elasticity required for normal bladder function ${ }^{3}$. Unlike the MUS, mesh sheets placed behind vagina had little testing prior to commercial release and can cause major de novo complications such as massive urine loss from "tethered vagina syndrome" 5,6 or nerve entrapment due to mesh shrinkage. Such complications are rarely, if ever, seen with MUS. ${ }^{1,2,4,6}$

There are many worrying aspects of the Cumberlege report as regards the MUS. Absent from the report is one critical detail: Cumberlage does not differentiate between slings and mesh sheets applied behind vagina, which are a very different technology from slings.

The science for ligament support of organs is well accepted. Ligaments are fundamental to Delancey's 1992 thesis of organ support, based on his extensive anatomical studies ${ }^{7}$. The 1990 thesis of Petros and Ulmsten , based on extensive animal and human studies ${ }^{1-4,6,8}$, emphasizes the role of collagen as the key structural component of ligaments; also emphasized is that the vagina requires elasticity for its role in bladder control 3 .

Slings implant narrow $1 \mathrm{~cm}$ tapes which harness the wound reaction from the implantation to create new collagen to reinforce weak ligaments, fig1. This is the core principle of the MUS and other sling operations. Slings attach the organs directly to the skeleton in a transverse manner, fig1. They have very little contact with the vagina, so they have very little opportunity to entrap nerves to cause de novo pain and they preserve vaginal elasticity needed for bladder function.

The Cumberlage report, though emphasizing the need for thorough scientific and clinical analysis for devices before being implanted in patients, has, in fact, abolished the most validated operation in the history of surgery. The MUS was not released until 1996, 10 years after the first animal experiments started in 1986, ironically, to test the safety and efficacy of the tape implantation, fig1, the very concern which seemed to dominate the Cumberlage report!

The animal testing included clinical monitoring over 3 months, anatomical studies, biomechanical testing of the neoligament on an Instron tensiometer, histology, bacteriology, radioactive Gallium studies, xray studies, regular biochemical and hematology testing of the animals ${ }^{8}$.

The first prototype operations commenced under strict EC surveillance between 1988 and 1993 at Royal Perth Hospital. They, too, were subjected to thorough clinical, bacteriological, radiological, hematological, biochemical, histological observations ${ }^{1,3}$. By the time the MUS was released in 1996, the MUS had undergone 10 years study for safety and efficacy under Ethics Committee surveillance in several international locations and after several published papers. Since 1996, the MUS has been the subject of $>1000$ scientific papers, (including 17year data), 10,000,000 MUS surgeries, endorsement by almost every learned body. By comparison, mesh sheet surgery for prolapse has had virtually no scientific testing. ${ }^{2}$

The poor anecdotal evidence presented by the Baroness Cumberlage for abolition of the MUS did not meet its stated clinical/scientific criteria. Quoted was not data, but one expert's singular case report of delayed onset of pelvic pain after MUS. As an expert, he should have known about Shull's famous observation ${ }^{9}$, that repairing one part of the vagina, such as a cystocoele, diverts pressure, to cause prolapse in another part of the vagina, for example, the apex. Apical prolapse is caused by decompensation of the uterosacral ligaments. Uterosacral ligament laxity is known to cause a number of co-occurring symptoms, pelvic pain, urge, frequency, nocturia, abnormal emptying, known collectively as the "posterior fornix syndrome" $4,5,6,10$. Pelvic pain is an important element in this syndrome. The posterior fornix syndrome should be excluded in cases of de novo pelvic pain occurring weeks or months after the original MUS operations. Cardinal/uterosacral ligament repair of the prolapse ${ }^{4}$ would most likely have cured the pain symptoms as reported by the singular Cumberlage expert. Clearly not considered by the Cumberlage report were next generation MUS slings ${ }^{11}$, $90 \%$ cure at 3 years, with no erosions at 3 years. They would put a whole new perspective on the Cumberlage complaints. 
One cannot extrapolate a series of individual cases, (undoubtedly worthy in themselves) to a general ban on the most documented operation in the history of surgery. As things stand in the UK, the $30 \%$ of women with SUI have very little to help them now. The scientific evidence needs to be re-assessed. Slings work by reinforcing ligaments; mesh sheets work by blocking descent, a totally different technology. Let's hope reason prevails, that the scientific evidence is reviewed and the Cumberlage "pause" is just that.

Conflicts No financial conflict of interest

Contribution Sole author

Funding Nil

Ethics NA

REFERENCES

1. Petros PE, Papadimitriou J Evolution of Midurethral and Other Mesh Slings - A Critical Analysis . Neurourol Urodyn. 2013 Apr;32(4):399-406. doi: 10.1002/nau.22308. Epub 2012 Sep 21.

2. Petros PEP Liedl B \& Darren Gold D Editorial Should surgeons continue to implant mesh sheets behind the vagina? International Urogynecology Journal (2018) 29:777-779

DOI: $10.1007 / \mathrm{s} 00192-018-3612-8$.

1. Petros PE \& Ulmsten U. An Integral Theory of female urinary incontinence. Acta Obstetricia et Gynecologica Scandinavica, 1990; 69; Supp.153: 1-79

2. Liedl B, Inoue H, Sekiguchi Y, et al. Is overactive bladder in the female surgically curable by ligament repair? Cent European J Urol. 2017; 70: 51-57

3. Williams G Browning A Petros PE The integral theory and its tethered vagina syndrome revisited: vaginal scarring may cause massive urinary incontinence Volume122 Issue4 October 2018 Pages 532-534 First published: 31 March 2018 https://doi.org/10.1111/bju.14218

4. Petros PE, Goeschen K,Inoue H Underactive bladder may be caused by uterosacral ligament laxity - a critical review of two paradigms Cent European J Urol. 2018; 71(4): 444-447. Published online 2018 Nov 9. doi: 10.5173/ceju.2018.1793

5. DeLancey JO. Anatomic aspects of vaginal eversion after hysterectomy. Am J Obstet Gynecol 1992;166:1717-24

6. Petros PE \& Ulmsten U, Papadimitriou J, The Autogenic Neoligament procedure: A technique for planned formation of an artificial neo-ligament . Acta Obstetricia et Gynecologica Scandinavica, Supplement 153, Vol 69, (1990), 43-51.

7. Shull B L, Capen C V, Riggs M W and Kuehl T J, Preoperative and postoperative analysis

of site specific pelvic support defects in 81 women treated with sacrospinous ligament

suspension and pelvic reconstruction, J. Obstet. Gynecol. (1992); 166; 1764-71.

Petros PE \& Ulmsten U. The posterior fornix syndrome: a multiple symptom complex of pelvic pain and abnormal urinary symptoms deriving from laxity in the posterior fornix . Scandinavian Journal of Urology and Nephrology 1993;27; Supp.153: 89-93.

Nakamura R, Yao M, Maeda Y, Fujisaki A, Sekiguchi Y Outpatient mid-urethral tissue fixation system sling for urodynamic stress urinary incontinence: 3-year surgical and quality of life results. Int Urogynecol J 2017 DOI 10.1007/s00192-017-3341-4

\section{Legend}

Fig. 1- Polypropylene tapes' $\mathrm{T}$ ' create new collagen (inset) to reinforce the 5 main suspensory structures - pubourethral (PUL), uterosacral (USL), arcus tendineus fasciapelvis (ATFP), Cardinal (CL), and perineal body $(\mathrm{PB})$. Tapes attach ligaments transversely to the skeleton and have very little contact with the vagina, very different from mesh sheets which are placed as a sheet behind the vaginal wall. 
Inset Figure from the original experiments in canines show formation of collagenous neoligaments formed by tapes.

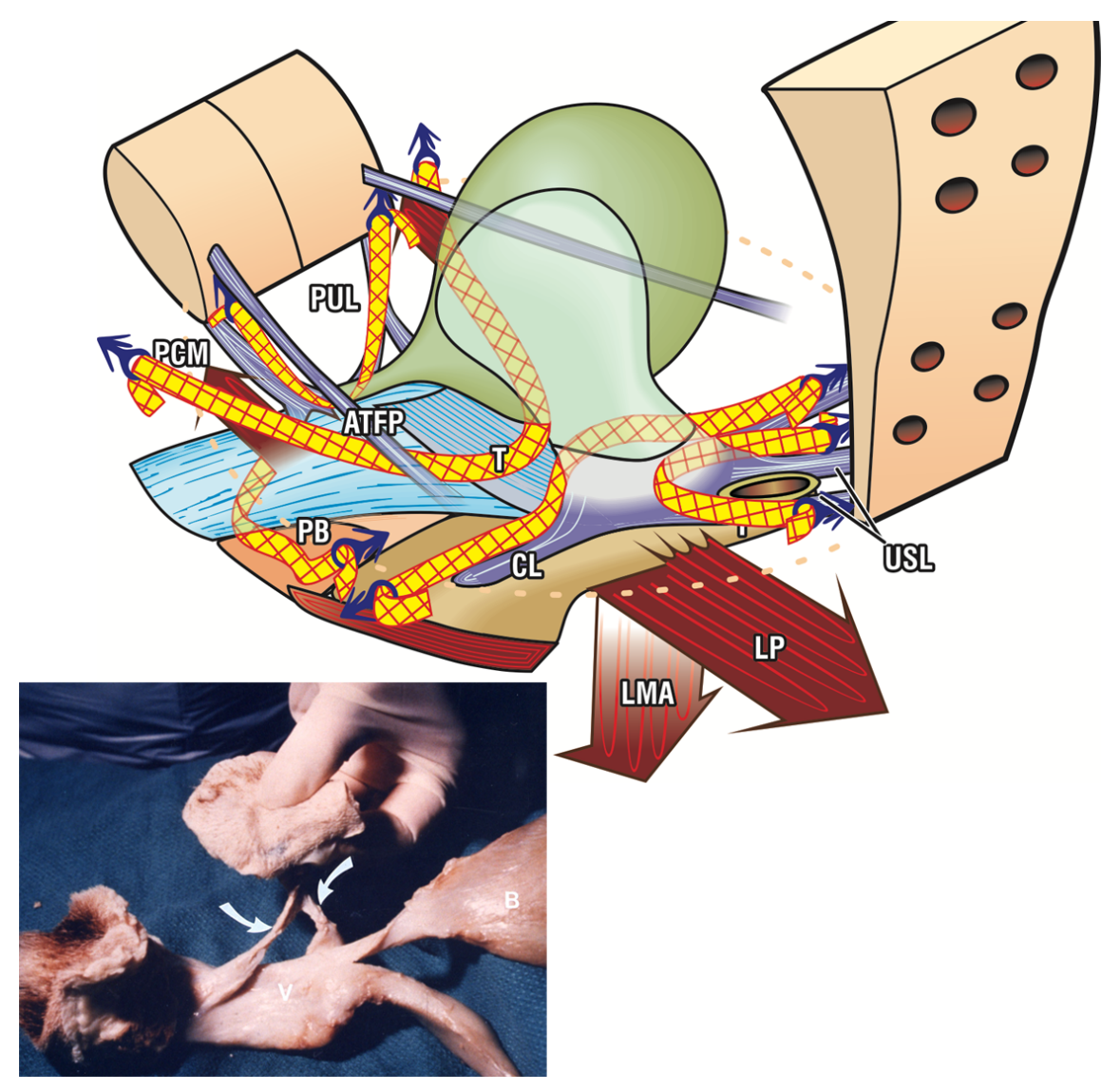

